\title{
The Use of Computer Models in the Software and Hardware Complex of Research Methods of Navigation Spacecrafts
}

\author{
Viktor N. Bondareva, Dmitry D. Dmitriev, \\ Nikolay S. Kremez ${ }^{\mathrm{b} *}$ and Valeriy N. Tyapkin ${ }^{\mathrm{b}}$ \\ ${ }^{a}$ VKO Military Academy named Marshal \\ of the Soviet Union Georgiy Zhukov \\ 50 Zhigareva Str., Tver, 170100, Russia \\ ${ }^{b}$ Siberian Federal University \\ 79 Svobodny, Krasnoyarsk, 660041, Russia
}

Received 01.09.2015, received in revised form 20.01.2016, accepted 31.01.2016

A description and capabilities developed computer models on research of methods developed highprecision navigation used in the software and hardware complex modeling processes positioning and measurement of the spatial orientation of the spacecraft at the low orbit and the GSO.

Keywords: GNSS Receiver, hardware-software complex, computer model, geostationary orbit.

Citation: Bondarev V.N., Dmitriev D.D., Kremez N.N., Tyapkin V.N. The use of computer models in the software and hardware complex of research methods of navigation spacecrafts, J. Sib. Fed. Univ. Eng. technol., 2016, 9(3), 302-309. DOI: 10.17516/1999-494X-2016-9-3-302-309.

(c) Siberian Federal University. All rights reserved

* Corresponding author E-mail address: Nkremez@sfu-kras.ru 


\title{
Использование компьютерных моделей
}

в программно-аппаратном комплексе

исследования методов навигации космических аппаратов

\author{
В.Н. Бондарев ${ }^{a}$, Д.Д. Дмитриев ${ }^{\sigma}$, \\ Н.С. Креме ${ }^{\sigma}$, В.Н. Тяпкин ${ }^{\sigma}$ \\ ${ }^{a}$ Военная академия ВКО \\ имени маршала Советского Союза Г.К. Жукова \\ Россия, 170100, Тверь, ул. Жигарева, 50 \\ ${ }^{6}$ Сибирский федеральный университет \\ Россия, 660041, Красноярск, пр. Свободный, 79
}

\begin{abstract}
Представлены описание и возможности разработанных компьютерных моделей по исследованию разработанных методов высокоточной навигачии используемых в программно-аппаратном комплексе моделирования процессов позииионирования и измерения пространственной ориентации космических аппаратов на низкой и геостационарной орбитах.
\end{abstract}

Ключевые слова: ГНСС-приемник, компьютерная модель, аппаратно-программный комплекс, геостаиионарная орбита.

\section{Introduction}

Application of GNSS receivers for navigation satellites of various types ranging from the idea to the realization of the specific active project is widely discussed in foreign and domestic sources. Considerable importance is given in the literature algorithmic methods of determining the location of the GSO spacecraft, used in low quantities of visible navigation spacecraft (NS) model of the motion of the spacecraft [1]. Issues of multi-GNSS receivers are also considered with autonomous navigation systems, operating on other principles (inertial, star, x-ray sensors). These techniques are more help in solving the problem of autonomous navigation definitions, but greatly complicate the equipment and does not guarantee accuracy. Regardless of the type of the system at a certain point there is a need to create a prototype system to evaluate all possible parameters in this case - of accuracy. Creating a hardware system for experimental studies associated primarily with economic costs not only for the manufacture of the modules of the system itself, but also for additional peripherals.

Nowadays more and more popular during the experimental studies are gaining mathematical modeling methods. The main advantage of these methods is a significant reduction in financial, time, labor costs of experiments. At the present stage of development of computer technology experimental studies using mathematical models will inevitably lead to the creation on their basis of a computer model, which should fully satisfy the conditions of the experiment.

Contribution of various disturbing factors precision motion prediction depends on the parameters of the spacecraft altitude orbit, elliptic, etc..., as well as mass-dimensional and aerodynamic characteristics of the spacecraft. The model of the gravitational field of the Earth (GFE) due to the continuous improvement of research methods, the use of satellite data and the rising volume of gravimetric measurements currently known with sufficient accuracy, allowing essentially to achieve

$$
-303-
$$


high accuracy and accounting gravitational perturbations in the simulation of spacecraft motion [2]. Gravitational perturbations from the Moon and the Sun are taken into account for any method of spacecraft motion simulation as well as the mass of the Sun and Moon, and the Moon's orbit and the Earth's currently known, with a high read accuracy of these problems. The simulation practice when creating models of spacecraft motion is usually simplified assessment applied, developed as a result of solving problems, summarizing many years of experience in operating a variety of spacecraft [3-5].

Thus, one of the main tasks of the developers of computer models, especially those related to the simulation of spacecraft orbital motion is possible a full account of all the disturbing factors that affect the result, as well as the choice of the method used, motion simulation, ie method for solving a system of differential equations describing the motion of the spacecraft.

Presented in this article version of hardware and software simulation positioning and measurement processes spacecraft spatial orientation at low and the GSO, is performed using a part of on-board equipment spacecrafts multi-GNSS receivers, allowing to carry out pilot studies developed methods and high-precision navigation algorithms for spacecraft based on the described computer models of spacecraft motion and visibility.

\section{Requirements for hardware-software complex}

Hardware-software complex modeling processes positioning and measurement of the spatial orientation of spacecraft at the low and GSO provides:

- automatic (without operator intervention) continuously day and night measurements of current navigation parameters;

- receiving of navigation signals from the minimum elevation angle $5^{\circ} \mathrm{NS}$ at least $24 \mathrm{NS}$;

- receive and process radio signals in all of radio visibility of GLONASS to L1, L2 frequency bands;

- receiving and processing GPS signals NS C / A code in the L1 frequency range;

- the allocation of the signals at the operational navigation data;

- receiving of navigation systems almanacs of preservation in non-volatile memory and the issuance of this information the controlling PC;

- the formation of signals similar to navigation signals GLONASS on the L1 and L2 frequencies and GPS at L1;

- monitoring and measurement of the parameters of simulated navigation systems GLONASS and GPS signals.

\section{Structure hardware-software complex}

Hardware-software complex modeling processes positioning and measurement of the spatial orientation of spacecraft at the low and the GSO is:

1) Hardware:

- two sets of layout multichannel GNSS receiver with an antenna system. multi-channel GNSS receiver layout. Two sets of measurements are used to estimate pseudo-navigation signals by NS difference methods;

- imitator GLONASS and GPS signals;

- instrumentation complete with calibrated antenna elements and feeder tract; 


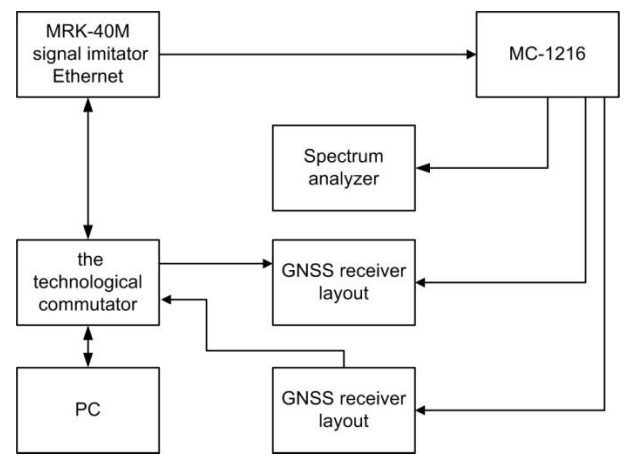

Fig. 1. Structural diagram of hardware and software

- a control the personal computer;

- technological cables, switches, power supplies, etc.

2) The software part:

- special software multi-channel GNSS receiver;

- a computer model of the spacecraft on-board navigation system based on the use of multiGNSS receivers, ensuring the implementation of the developed methods of navigation and high-precision measurement of the spatial orientation of the spacecraft at the low and the GSO;

- a computer model of the navigation field at a given point on the BUT spacecraft orbit and the GSO;

- the system software.

Structural diagram of hardware and software modeling processes positioning and measurement of the spatial orientation spacecraft at low and the GSO is shown in Fig. 1.

Using the simulator signals of GLONASS and GPS signals are generated NS, are fed to the transmitter antenna or directly to the input of multi-channel GNSS receiver layout. The layout of multichannel GNSS receiver receives and processes navigation signals in accordance with the established methods of navigation and high-precision measurement of the spatial orientation of the spacecraft at the low and the GSO.

With the help of a personal computer made management simulator layout and navigation signals GNSS receiver using the developed computer models of spacecraft motion and visibility of the low and GSO. Control of navigation signals received power is performed using a spectrum analyzer.

\section{Computer models of hardware-software complex}

Computer models of spacecraft on-board navigation systems based on the use of multi-GNSS receivers emulate the navigation system in accordance with the methods developed high-precision navigation:

- high-precision navigation and spatial orientation measurement of spacecraft at the low and the GSO, based on the use of a part of on-board equipment of spacecrafts multi-GNSS receivers;

- processing inter-satellite and passive measurements and calculation of ephemeris-time information on spacecraft slot autonomous operation.

$$
-305-
$$


Also simulate the orbital motion of the navigation spacecraft and spacecraft in the low and the GSO and in accordance with the calculated relative position of navigation spacecraft and spacecraft in the low and the GSO, the Earth and the navigation spacecraft form the antenna pattern allow us to count the received radio navigation signal.

1) Specifications of computer models:

- measuring the current position and spatial orientation - using all available spacecraft GLONASS and GPS within visibility zone;

- measuring the current position and the spatial orientation of spacecraft on low - single-step methods for spacecraft in GEO - dynamic methods;

- the accuracy of the measurement of the current position and spatial orientation:

a) spacecraft coordinates by using spacecraft GLONASS and GPS signals with a standard error of no more than: at low - $15 \mathrm{~m}$, the GEO - $1000 \mathrm{~m}$;

b) speed with standard error of no more than $0.1 \mathrm{~m} / \mathrm{s}$;

c) spatial orientation angles using the antenna system with the basic distance between the antenna modules $0.7 \mathrm{~m}$ : a systematic error of no more than $10^{\prime}$ and a standard deviation of not more than $20^{\prime}$ to low orbit.

2) Results of work:

- location coordinates and the vector waypoint speed and angles of spatial orientation of the antenna post and related spacecraft at work on all signals of GLONASS spacecraft and GPS;

- issuing on-board control spacecraft current position of the main antenna unit of the antenna system of fasting, his velocity vector, the spatial orientation of the antenna station and related facilities;

- reception, storage and updating of the almanacs of GLONASS and GPS and recommendations for observing sessions at any given time.

3) Capabilities:

- calculation of the coordinates of space and ground speed vector of the antenna post of movement and related spacecraft at work on all signals of GLONASS satellites and GPS;

- automate the process of calculating the number of simultaneously observed the NS for a given point of standing spacecraft in low and GEO;

- calculation of spatial orientation angles of the antenna post and related spacecraft at work on all signals of GLONASS satellites and GPS;

- automation of the process of determining the location of the NS at a given time according to the almanac;

- simulation of GLONASS signals and GPS;

- interactive selection of the type received navigation signals to be processed;

- live view in the number of simultaneously observed the NS for a given point of standing spacecraft in low and GEO;

- Interactive NS view created a power flux density of radio navigation signals, depending on the parameters defined by the location and the receiver sensitivity, shape pattern of the receiving antenna;

- interactive selection of the type and parameters (amplitude, letters and Doppler frequency) of simulated navigation signals; 
- interactive selection of the type used by the navigation system;

- interactive selection of the type and configuration of antennas GNSS receiver systems;

- preservation of the results of the data files with the possibility of further processing by external programs.

4) Interface computer model:

Computer model of spacecraft on-board navigation system includes the following modules:

- measurement of the current position of the main antenna unit;

- measurement of the spatial orientation of the antenna post;

- calculation of the location of navigation spacecraft;

- simulating GLONASS and GPS signals.

- determining the coordinates of GLONASS and GPS according to the almanac;

- determination of spacecraft coordinates on the low orbit;

- calculating the signal visibility areas of the NS points standing spacecraft in geostationary orbit and spacecraft at low orbit.

Computer model of spacecraft on-board navigation system NS has a graphical interface that is created using the built-in functions Qt Creator 2.7.0 application software. The main window of computer models designed to display the control buttons, the input fields for the user service information and graphical display of the results. Distribution panels shown in Fig. 2 and Fig. 3.

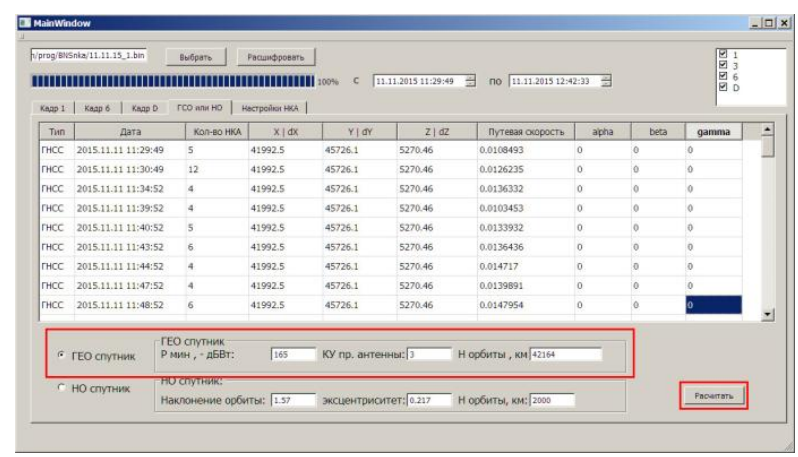

Fig. 2. Distribution №1 computer model of the main window panels

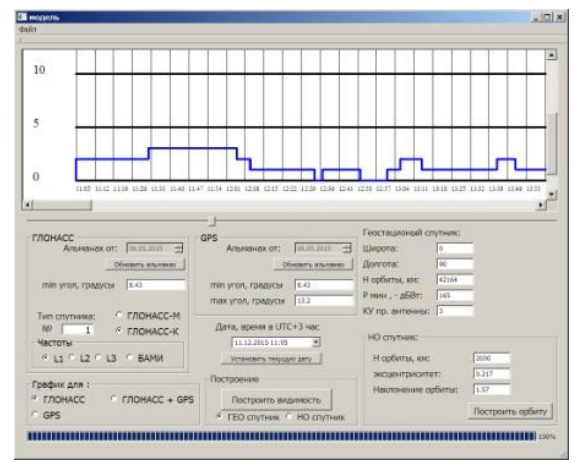

Fig. 3. Distribution №2 computer model of the main window panels

$$
-307-
$$




\section{Description of work computer models}

The results of measurements on all the components of hardware and software enter the measurement results processing module from the GNSS receiver layout. This module computes the errors introduced by the block for digital signal processing (UDSP) on the set parameters simulated navigation signals.The input data for computer models via an Ethernet network protocols VIN serve as frames service information GNSS receiver MRK-101, as provided for carrying deferred experiment using archival file upload data frames generated by MRK-101 equipment.During the field experiment is an accumulation of measurement results with the hardware and software system with the subsequent processing of the results obtained on completion of the experiment.

Working computer model begins with the reception of data to simulate the formation of the navigation signals and almanacs GLONASS and GPS by means of a protocol VIN: module simulating GLONASS signals and GPS information comes out of the frame of the primary processing of measurement $(0 \mathrm{Dh})$ containing the results of the measurements taken by the navigation parameters of the NS; module positioning navigation satellites GLONASS and GPS almanac according to the information supplied from the frame almanacs GLONASS and GPS (07h) containing information received directly from the navigation signal NS, on the status of the satellite constellation and the said SRNS data to predict the NS visibility.Feature module simulating GLONASS signals and GPS to provide the user the ability to set and save the original settings of the observed scenario navigation signals according to the mathematical model or the real situation recorded.

Depending on the experimental conditions, calculation of the coordinates of navigation satellites produced in the module for calculating the location of navigation satellites to instant ti according to the operational information contained in the navigation frames or module positioning navigation satellites GLONASS and GPS according to the almanac. Calculation of the ephemeris of the GLONASS and GPS is made in the same manner. First, the data is decrypted operational information. Then, according to operational information made a correction parameter navigation. Next are calculated ephemeris for a predetermined measurement time.

According to the set parameters of spacecraft orbits on low orbit in determining the coordinates of the spacecraft module on low orbit calculates the coordinates and the vector components of the spacecraft velocity but at the time ti. Further data from the above-described modules receives a calculation module zones navigation signals appear spacecraft dots standing spacecraft in geostationary orbit and spacecraft into low orbit which is formed by satisfying the task group NS and power calculation navigation signals flux density depending on the defined location parameters and receiver sensitivity, shape directional pattern receiving antenna for a given time.

On the basis of the group in the NS module measuring the current position of the main antenna module calculates the coordinates of space and ground speed vector of the antenna post of movement and related spacecraft to low orbit or GSO. And further unit of measurement of the spatial orientation of the antenna post calculates spatial orientation angles geocentric coordinate system antenna post and associated spacecraft him.As a result of the computer model can assess the accuracy of positioning and measurement of spacecraft orientation using developed methods of calculation of ephemeris-time information obtained by comparing the measurement results with the calculated data. 


\section{Implementation and its prospects}

Using the computer model navigation field at a given point on the orbit of spacecraft low orbit and GEO are calculated and the received radio navigation signal power in accordance with the calculated relative position and navigation satellites and spacecraft on low orbit and GSO earth form and radiation pattern of the antenna of the navigation spacecraft. The calculation results are used for planning sessions, inter-satellite measurement and calculation of geometrical factor that significantly affects the accuracy of navigation measurements.Using the output of computer models not only managed to prove the possibility of using GNSS receiver for precise navigation spacecraft in geostationary orbit in reduced radio coverage, but also to estimate the minimum required parameters of the main technical characteristics of the requirements for GNSS receivers are part of the onboard spacecraft navigation equipment. Also described computer models as part of hardware and software provide opportunities for testing new methods of goniometric measurements of navigation in the navigation equipment for users of global navigation satellite systems in the design stages of the GNSS receiver that allows you to test not only the developed algorithms, as well as a receiver as a whole.

\section{Acknowledgment}

The work was supported by the Ministry of Education and Science of the Russian Federation (agreement № 14.575.21.0081, unique ID project RFMEFI57514X0081).

\section{References}

[1] Fateev, Yu.L., Dmitriev, D.D. ; Tyapkin, V.N. ; Kremez, N.S. ; Ratushnyak, V.N., The use of GNSS technologies for high-precision navigation geostationary spacecraft, pub. 2015 International Siberian Conference on Control and Communications, SIBCON 2015 Proceedings, 2015.

[2] Лысенко Л.Н., Бетанов В.В., Звягин Ф.В. А.Г., Булах К.Г. Теоретические основы баллистико-навигационного обеспечения космических полетов. М.: МГТУ им. Н.Э. Баумана, 2014. 518 c [Lysenko L.N., Bethanov V.V., Zvyagin F.V. Theoretically bases of ballistics navigation spaceflight support, pub. House of the MSTU. N.E. Bauman, 2014, 518 p. (in Russian)]

[3] Бартенев В.А., Гречкосеев А.К. Гарантированная оценка точности коррекции эфемерид ИСЗ по межспутниковым измерениям. Радиотехника, 1998, 9. [Bartenev V.A., Grechkosee A.K. The guaranteed accuracy estimation for the satellite ephemeris correction between satellite measurements, Radio engineering, 1998, 9 (in Russian)]

[4] Сурнин Ю.В. и др. Программа прогнозирования движения геодезических искусственных спутников Земли. Наблюдения ИСЗ, 1977, № 16. [Bartenev V.A., Grechkosee A.K. The program predict the movement of geodetic artificial satel-nicks Earth, Surveillance satellite, 1977, 16 (in Russian)]

[5] Забокрицкий А.В. и др. Технологии навигационно-баллистического обеспечения полетов космических средств. Баллистика вчера, сегодня и завтра. ВКА им. А.Ф. Можайского, 2006, 82-97 [Bartenev V.A., Grechkosee A.K. Technology navigation and ballistic Aviation cosmicray funds, Ballistics yesterday, today and tomorrow, 2006, 82-97 (in Russian)] 